\title{
Uma proposta para o ensino da compreensão leitora em uma concepção de educação cognitiva
}

\author{
Elenice Andersen*
}

\begin{abstract}
Resumo
Este trabalho objetiva propor uma reflexão sobre o ensino da compreensão leitora, a partir de uma abordagem de educação cognitiva para o desenvolvimento humano pleno. Para isso, inicialmente, discute a concepção de educação cognitiva, de Fonseca (FONSECA, 2015) e, em seguida, realiza a revisão narrativa de três programas de ensino da leitura, desenvolvidos no Brasil, Portugal e Espanha. A partir dessa revisão, identifica os pontos de convergência entre os programas, interpretando-os como o baluarte de um ensino eficaz para o desenvolvimento da compreensão leitora. Contudo, observa que, nesses programas, os aspectos emocionais da leitura ainda figuram em segundo plano e defende que as estratégias de ensino precisam considerar os achados da literatura neurocientífica sobre a indissociabilidade cognição-emoção (DAMÁSIO, 2012). Dessa forma, propõe que a reflexão seja ampliada para uma concepção de educação cognitiva que integre os aspectos cognitivos e emocionais, com vistas ao desenvolvimento humano mais integral e não apenas focado no domínio cognitivo e no bom desempenho escolar, mas também na satisfação pessoal com a leitura e na experimentação de como as emoções interagem com a compreensão leitora.
\end{abstract}

Palavras-chave: Leitura. Compreensão Leitora. Cognição. Emoção. Ensino.

\section{Una propuesta para la enseñanza de la comprensión lectora en una concepción de la educación cognitiva}

\begin{abstract}
Resumen
Este trabajo objetiva proponer una reflexión sobre la enseñanza de la comprensión lectora, a partir de un enfoque de educación cognitiva para el desarrollo humano pleno. Para ello, inicialmente se analiza la concepción de la educación cognitiva de Fonseca (FONSECA, 2015) y, a continuación, realiza la revisión narrativa de tres programas educativos de lectura, desarrollados en Brasil, Portugal y España. La revisión identifica los puntos de convergencia entre los programas, interpretándolos como el baluarte de una enseñanza eficaz para el desarrollo de la comprensión lectora. Sin embargo, observa que, en estos programas, los aspectos emocionales de la lectura todavía se enumeran de acuerdo con lo planeado y, argumenta, que las estrategias de enseñanza necesitan considerar los descubrimientos de la literatura neurocientífica sobre el indi-relación de la cogniciónemoción (DAMASIO , 2012). De esta forma, propone que la reflexión sea ampliada para una concepción de educación cognitiva que integre los aspectos cognitivos y emocionales, con vistas al desarrollo humano más integral y no solamente en el dominio cognitivo y en el buen desempeño escolar, sino también en la satisfacción personal con la lectura y en la experimentación de cómo las emociones interactúan con la comprensión lectora.
\end{abstract}

Palabras clave: Lectura. Comprensión. Cognición. Emoción. Educación.

Recebido: $15 / 01 / 2018$

Aceito: $12 / 04 / 2018$

\footnotetext{
* Doutora em Linguística pela Pontifícia Universidade Católica do Rio Grande do Sul. Professora Associada em exercício na Universidade Federal de Santa Catarina.
} 


\section{Introdução}

Neste trabalho, compartilhamos do pensamento de educação para o desenvolvimento humano mais pleno, consubstanciado pela integração dos aspectos cognitivos e afetivos nas estratégias de ensinoaprendizagem. Particularmente, discorremos sobre essa integração com foco no processo de ensinoaprendizagem da compreensão leitora. Apresentamos argumentos teóricos contrários ao pensamento de que a educação cognitiva possa ser dissociada do aspecto emocional do desenvolvimento humano. Considerando os fundamentos neurocientíficos sobre a indissociabilidade cognição-emoção (DAMÁSIO, 2012; FONSECA, 2015; ALMEIDA, 2015; COSENZA e GUERRA, 2011), defendemos que, se o aspecto afetivo não é posto em relevo nas práticas de ensino da compreensão leitora, ele não deixa de estar ali presente, influenciando as práticas desse ensino e por elas sendo influenciado, e, uma vez ignorado, ocasiona uma formação incompleta.

O avanço científico na área cognitiva, sobre a compreensão da leitura, proporciona hoje um conjunto de evidências que permitem subsidiar com maior clareza o planejamento didático e o desenvolvimento de ações para promover a proficiência em leitura e compreensão leitora; permite-se, assim, que o ensino seja realizado com textos apropriados, com tarefas e perguntas que contemplem os variados processos envolvidos na leitura, tais como a elaboração de inferências, a memória, a mobilização do conhecimento de mundo, a extração de significado, a reorganização mental do texto, a capacidade de resumi-lo, a compreensão crítica e a consciência textual (PULIEZI, 2015). Contudo, quanto à inserção do avanço dos estudos neurocientíficos sobre a integração cognição-emoção, ainda não há um investimento expressivo em pesquisas na área, que prezem as diretrizes científicas da aprendizagem baseada no cérebro, as quais, atualmente, põem em relevo o papel das emoções na cognição.

Nesse sentido, este trabalho busca contribuir para a pesquisa na área e para projetos de ensino da compreensão leitora na escola, em uma perspectiva mais ampla, integradora do desenvolvimento humano e favorável à aprendizagem, contemplando explicitamente o aspecto emocional da leitura. Para tal, realizamos uma revisão narrativa de três programas de ensino da compreensão leitora, desenvolvidos no Brasil, Portugal e Espanha, filiados teoricamente às ciências cognitivas e empiricamente validados, buscando identificar os pontos de convergência entre eles, interpretados como o fundamento de um ensino de base cognitiva eficaz, e refletindo sobre a relação desse ensino com uma concepção de educação cognitiva mais integradora, que busca maximizar os potenciais cognitivos do aluno, mas também promove sua satisfação pessoal com a leitura, com vistas ao desenvolvimento humano pleno.

Considerando nosso propósito, em um primeiro momento, explicaremos a abordagem de educação cognitiva, conforme Fonseca (2015), apresentando, ao mesmo tempo, pensamentos de outros pesquisadores que corroboram nossos argumentos. Na segunda seção, realizamos a revisão narrativa dos programas de ensino da compreensão leitora supracitados, buscando identificar os pontos de convergência entre eles quanto aos aspectos cognitivos considerados essenciais a esse ensino, à mediação docente e às pistas da integração cognição-emoção subjacentes às práticas propostas. Em seguida, discutimos as limitações dos programas quanto à integração cognição-emoção e elaboramos sugestões para minorar essas limitações. Por fim, na conclusão, demonstramos a urgência da incorporação do conhecimento neurocientífico sobre o papel das emoções humanas nas práticas de ensino da compreensão da leitura e propomos uma agenda de pesquisas na área. 


\section{0 processo de ensino-aprendizagem numa abordagem da educação cognitiva}

Neste trabalho, compartilhamos do pensamento de educação humana integral em contraponto à educação ancorada exclusivamente no racional. A supervalorização histórica da razão sobre as emoções, oriunda da busca de cientificidade, em nosso entender, não se sustenta mais, sobretudo a partir das novas descobertas da neurociência, que têm trazido evidências da estreita interação entre cognição e emoção. Com base na literatura neurocientífica, especialmente a respeito da indissociabilidade razão-emoção (DAMÁSIO, 2012 [1994]), entendemos que o sensível, o perceptual e o emocional são constitutivos do processo cognitivo da aprendizagem e, por isso, precisam ser trabalhados em conjunto para o desenvolvimento humano pleno. É nessa perspectiva que compreendemos a educação cognitiva.

A concepção de educação cognitiva pode variar bastante a depender do autor, mas, em linhas gerais, identifica o uso do conjunto do conhecimento em cognição aplicado aos procedimentos pedagógicos. Fonseca (2015), amplamente apoiado na literatura neurocientífica, defende uma abordagem cognitiva da aprendizagem humana com uma visão multifacetada, que inclua as bases neuropsicológicas da cognição e da aprendizagem. Essa visão, segundo o autor, é necessária porque qualquer aprendizagem envolve uma complexa arquitetura de processos e subcomponentes cognitivos, que integra uma organização articulada de processos de atenção e vigilância, de processos de integração e retenção, de processamentos sequenciais e simultâneos de dados multimodais e de procedimento de planificação e expressão da informação. Esses processos evoluem e se inter-relacionam sistematicamente no cérebro e, assim, compreender como ocorre aproxima os profissionais da educação do conhecimento sobre as funções, capacidades, habilidades ou competências cognitivas da aprendizagem (FONSECA, 2015, p. 62).

Na abordagem da educação cognitiva, o processo de ensino-aprendizagem visa ao desenvolvimento dos indivíduos. Sua finalidade principal é a de proporcionar ferramentas psicológicas que permitam maximizar a capacidade de aprender a aprender, de aprender a pensar e a refletir, de aprender a transferir e a generalizar conhecimentos e de aprender a estudar e a comunicar, muito mais do que a memorizar e reproduzir informação (FONSECA, 2015, p. 9-10), como ocorre nos modelos tradicionais de ensino.

Assim, ainda segundo o autor, aprender a refletir, a raciocinar, a utilizar estratégias de resolução de problemas é uma forma de adaptarmos as novas gerações para aprenderem mais, melhor e de forma diferente, flexível, cooperativa e não competitiva, o que é uma necessidade fundamental da educação e, provavelmente, a tarefa mais relevante da escola. Em seu ponto de vista, é dever dos governos proporcionar as condições para que a escola garanta que todo estudante tenha o direito de desenvolver ao máximo o seu potencial cognitivo.

Afora isso, outro aspecto a ser considerado é que o trabalho integrado em educação, com diferentes estímulos na interação com o meio social, proporciona os instrumentos necessários para a formação da personalidade e a construção do conhecimento, que terão reflexos na idade adulta (SCHIAVO; RIBÓ, 2007). Os estímulos emocionais, que estão relacionados à interação, aos sentimentos, desejos e ansiedades, favorecem a maior facilidade na socialização com outras pessoas, maior segurança na hora de expressar sentimentos e medos, melhor compreensão dos outros e do ambiente ao seu redor, ao mesmo tempo em que é construída a bagagem de valores. Quanto maiores as estimulações físicas, afetivas e sociais, maior será o enriquecimento da inteligência, tornando o aluno mais ativo, dinâmico, criativo, emocionalmente equilibrado e capaz de encontrar soluções a problemas e apresentar uma boa socialização, o que se espera de uma educação voltada para um desenvolvimento mais pleno (idem).

Também é importante assinalar que a cognição, nessa abordagem, não se resume à simples adição da atenção, da memória, da codificação e da planificação da informação, mas à integração multicomponencial de funções cerebrais, em que a aprendizagem é entendida como um imenso e 
complexo evento neurológico. O ensino de competências cognitivas não é ignorado, por assumir que estas não possam ou não precisem ser ensinadas ou que elas emerjam automaticamente por maturação neuropsicológica; porém, a capacidade de pensar se desenvolve por meio de mediatização contínua:

A educação cognitiva encerra a visão dialógica do desenvolvimento cognitivo humano, uma construtivista e outra coconstrutivista. A construtivista, inspirada em Piaget, visa a construção centrípeta, significativa e estruturada do conhecimento, e não a pura acumulação acrítica de dados de informação. A coconstrutivista, inspirada em Vygotsky, reforça a construção centrífuga do conhecimento com base em interações sociais interiorizadas e mediatizadas envolvendo um diálogo intencional entre indivíduos experientes e inexperientes. (FONSECA, 2015, p. 08. Grifos do autor).

A educação cognitiva objetiva, portanto, a otimização máxima possível do potencial de aprendizagem de estudantes, o que consiste, de forma sumária, em desenvolver e maximizar os processos de captação, integração, elaboração e expressão da informação em um entendimento de integração entre cognição e afetividade, com a responsabilidade social de desenvolver os recursos humanos em qualquer idade, condição ou contexto, identificando os obstáculos que bloqueiam a aprendizagem ou que a impedem de florescer, envolvendo a simultaneidade da integridade neurobiológica e a presença de um contexto social facilitador com mediatizadores afetuosos, com reciprocidade emocional (FONSECA, 2015).

Destarte, para nós, proporcionar aos educadores esse novo olhar propicia a aproximação docente do conhecimento ontogenético e do conhecimento de estratégias de ensino essenciais para a aprendizagem, favorecendo o desenvolvimento humano. No entanto, a escola e a maioria das instituições sociais envolvidas na formação e qualificação dos recursos humanos têm negligenciado as vantagens da educação cognitiva (FONSECA, 2015). ${ }^{2}$ Evidentemente, é um desafio o fato de que assumir essa perspectiva implica reverter a ideia cartesiana de uma mente separada do corpo, um erro que, como bem protesta Damásio (2012), leva muitos cientistas cognitivos a querer explicar a mente apenas em termos de fenômenos cerebrais, "deixando de lado todo o restante do organismo e o meio ambiente físico e social - e, por conseguinte, excluindo o fato de parte do próprio meio ambiente ser também um produto das ações interiores do organismo" (DAMASIO, 2012., p. 220).

Discordando da visão essencialmente cartesiana para a educação, em nosso entender, são as estimulações físicas, afetivas e sociais, intencionalmente planejadas para um trabalho integrado, que proporcionam ao aluno um avançar no conhecimento e no seu desenvolvimento. Entendemos, igualmente, que isso também é válido e necessário para o ensino da compreensão leitora, uma vez que há evidências da relação cognição-emoção em leitura. León et al. (2015), por exemplo, investigaram o papel da ativação de inferências emocionais quando os leitores representam os estados emocionais de personagens fictícios, e os resultados mostraram que a valência foi fator determinante no momento em que a inferência emocional foi gerada, sendo a valência positiva mais rápida do que a negativa. Em outro estudo, Citron et al. (2014) defenderam que o conteúdo emocional de um material verbal afeta a leitura, e o processamento perceptual é melhorado por meio de estímulos emocionalmente salientes. Em se tratando especificamente da leitura em nível textual, Castro (2004) verificou que textos que apresentam conteúdo emocionante são significativamente mais bem recordados que textos neutros. Larroza (2001) verificou a correlação positiva entre emoção positiva em leitura e a compreensão leitora.

Entretanto, a mediação docente planejada para uma estimulação cognição-emoção é, ainda, um desafio, na medida em que as propostas pedagógicas continuam muito conteudistas. Muitos projetos de ensino sequer empregam o conhecimento sobre cognição nas práticas de ensino da compreensão leitora, fato que revela o longo caminho a se percorrer. Infelizmente, o ensino da compreensão leitora, por vezes, é confundido com a simples prática de aplicação de tarefas de avaliação da compreensão;

2 Fonseca (2016) considera que a educação cognitiva deve atravessar todos os níveis de ensino, da Educação Infantil ao Ensino Superior. 
porém, existem programas de compreensão leitora que ultrapassaram essas barreiras e valorizaram mais profundamente o conhecimento da ciência cognitiva. Na próxima seção, realizamos uma revisão narrativa de três desses programas, escolhidos por sua sólida fundamentação teórica em cognição e por sua validação empírica.

\section{0 ensino da compreensão leitora em três programas de abordagem cognitiva}

Por muito tempo, o ensino da compreensão leitora tem sido negligenciado e reduzido à proposição de tarefas de interpretação textual. Subjacente a essa prática está a ideia de que o desenvolvimento dessa compreensão é espontâneo e gradativo, conforme a maturação neuropsicológica. Nessa visão, a criança, aos poucos, avançaria em suas habilidades cognitivas e desenvolveria habilidades cada vez mais complexas de compreensão leitora, cabendo ao professor tão somente fornecer os textos adequados a cada etapa do desenvolvimento e elaborar questões sobre esses textos.

Essa perspectiva encontra respaldo em trabalhos que elencam fases ou estágios de desenvolvimento do leitor. Podemos citar, como exemplo, o trabalho bem conhecido de Jeanne Chall (1983) sobre os estágios do desenvolvimento da capacidade de leitura, fundamentado na teoria de Jean Piaget. No modelo dessa autora, há cinco estágios de desenvolvimento da capacidade de leitura, começando pelo estágio da pré-leitura (do nascimento até os seis anos), passando pelo estágio de leitura inicial ou decodificação (dos seis aos sete anos), pelo estágio de fluência (dos sete aos oito anos) e pelo estágio de leitura para aprendizagem (dos nove aos quatorze anos), até atingir os estágios de pontos de vista múltiplos (dos quatorze aos dezesseis anos) e o de construção e reconstrução de uma visão mundial (acima de dezoito anos).

No Brasil, também é bastante conhecido o trabalho de Coelho (2000), que propõe a adequação dos textos literários às diferentes etapas piagetianas do desenvolvimento psicológico infantil e juvenil, por considerar que, embora possa haver certa variação na evolução biopsíquica, a natureza e a sequência dos estágios são iguais para todos. Com isso, a autora sugere estas fases de desenvolvimento do leitor: pré-leitor (fase que abrange uma etapa inicial que vai dos quinze meses aos três anos e uma segunda etapa que começa a partir dos dois/três anos); leitor iniciante (a partir dos seis/sete anos); leitor em processo (a partir dos oito/nove anos); leitor fluente (a partir dos dez/onze anos); e leitor crítico (a partir dos doze/treze anos).

Nas duas interpretações dos estágios de desenvolvimento da leitura, podemos encontrar pontos em comum: ambas propõem estágios que evoluem da pré-leitura, passando por um estágio de leitura inicial, um estágio de desenvolvimento da fluência, chegando a um estágio de leitura mais crítica. Podemos observar, também, a forte influência da psicologia genética subjacente à disposição desses estágios, o que, de certa forma, sustenta as interpretações das autoras. De fato, a maturação cognitiva, em condições normais, por si só, representa a ampliação das capacidades de compreensão leitora da criança, conforme seu pensamento evolui e se torna mais elaborado. Por essa razão, é amplamente aceito entre os educadores que assumem a abordagem genética piagetiana o pressuposto de que a faculdade de raciocínio de cada indivíduo está relacionada a períodos de desenvolvimento, caracterizados em função das capacidades cognitivas que o indivíduo dispõe em cada etapa para depreender e organizar a realidade. Entretanto, esse pressuposto, sem um exame mais cuidadoso, frequentemente, leva os professores que trabalham com a linguagem a conceber a compreensão leitora como parte de um processo de desenvolvimento cognitivo espontâneo da criança, de modo que o seu ensino seria desnecessário e, para sua abordagem em sala de aula, bastaria o uso de tarefas de compreensão leitora. 
Contudo, é importante lembrar que um dos pressupostos da própria abordagem genética é a conviç̧ão de que, na origem do conhecimento, há um processo dinâmico de permanente interação entre o sujeito e o objeto, de modo que as práticas pedagógicas têm um papel relevante para auxiliar o aluno a avançar nas capacidades cognitivas. Por isso, entendemos que programas com validação empírica que apresentem estratégias de mediação docente são altamente recomendáveis para um ensino com foco no desenvolvimento do leitor. Esse é o caso dos programas elaborados por Lopes e Tapia (2016), Viana (2002) e Kleiman (2013 [1993]). Por essa razão, a partir deste momento, procedemos à revisão narrativa das propostas elaboradas por esses autores. Antes, porém, cumpre-nos destacar que, tendo em vista os nossos objetivos, a pesquisa de revisão bibliográfica narrativa examinou obras monográficas publicadas em livro impresso ou digital que (i) descrevessem programas de intervenção com sólida base cognitiva e empiricamente validados quanto à sua eficácia em contextos de ensino reais e amplos, (ii) tivessem por foco exclusivo o ensino da compreensão da leitura, (iii) se sustentassem em argumentos que defendem a tese da viabilidade desse ensino e (iv) descrevessem de forma pormenorizada as estratégias adotadas em seu programa. Além disso, pela concepção de educação que objetivamos, conforme comentamos anteriormente, foi considerado como fundamental o fato de as obras descreverem as estratégias interativas de mediação docente necessárias à aprendizagem da compreensão leitora. Nosso objetivo foi o de identificar os pontos de convergência entre as propostas, interpretando-os como o baluarte das estratégias cognitivas de ensino. Ademais, como já expusemos, buscamos, igualmente, identificar pistas de estratégias de integração entre os aspectos cognitivos e emocionais, com vistas à nossa reflexão sobre possibilidades de um ensino da compreensão leitora voltado para o desenvolvimento humano pleno.

O primeiro trabalho que revisamos foi o dos espanhóis Lopes e Tapia (2016). Esses autores entendem a compreensão leitora como um processo que tem por base a interação entre o leitor e o texto, cabendo ao leitor relacionar a informação proporcionada pelo autor com aquela que tem armazenada na memória e, a partir disso, fazer inferências sobre o texto. Portanto, para compreender um texto, o leitor deve ser capaz de compreender que a organização e a estrutura das ideias desse texto dizem respeito ao que o autor quer comunicar e de relacionar as ideias do texto às ideias armazenadas no cérebro. A compreensão da leitura é, assim, o resultado de um processo interativo que o leitor realiza com o texto, em diferentes níveis - lexical, sintático, semântico e referencial, e que envolve tanto as variáveis textuais, como as do leitor. Lopes e Tapia ressaltam, porém, que o processo de compreensão não se encerra na análise semântica, pois o leitor continua com a construção de uma representação mental do conteúdo que o texto descreve, para o qual utiliza tanto o conhecimento prévio sobre o conteúdo quanto a informação oferecida por ele. E, dessa forma, a representação do significado do texto será tanto mais produtiva quanto já se tenha trabalhado adequadamente com cada um dos diferentes níveis.

Com base nesses pressupostos, Lopes e Tapia (2016) elaboraram e validaram um programa de ensino de estratégias de compreensão leitora. O programa consiste em um conjunto de estratégias trabalhadas de forma sequencial. Primeiramente, a proposta orienta para a ativação do conhecimento prévio sobre o tema, os conceitos e o vocabulário. O segundo passo refere-se a um trabalhar conjuntamente a estrutura textual, o que, para os autores, significa identificar a forma como o autor organiza suas ideias e determina, em grande parte, o que constitui a ideia principal do texto. Em seguida, recomendam o trabalho com a representação hierárquica das ideias do texto, em um processo de seleção das mais importantes, bem como o estabelecimento das relações mais relevantes, cujo resultado é uma representação hierárquica de diferentes níveis de importância que ajudam na identificação da ideia principal do texto. Por fim, os autores sugerem a produção textual, como estratégia de apoio para consolidar o processo de aprendizagem das diferentes estruturas textuais em função das intenções comunicativas, favorecendo a consciência. 
As estratégias dos autores, embora notoriamente simples em sua concepção de ensino da compreensão leitora, foram suficientes para ter sua efetividade comprovada. A partir de um curso de formação docente, com vinte e seis professores, de quinhentos e noventa alunos dos anos finais da educação básica, os autores comprovaram empiricamente que o programa foi uma ferramenta útil para a formação de professores, uma vez que sua atuação se aperfeiçoava após o curso de formação, e a mudança se traduzia em melhorias no rendimento dos alunos. Esse fato evidencia que o ensino estruturado de estratégias cognitivas elementares, como as de ativar o conhecimento prévio do leitor, familiarizar os alunos com a estrutura do texto e conduzi-los a perceber seus próprios processos de compreensão e elaboração, de modo que sejam capazes de revisá-los e autorregulá-los, já oferece uma contribuição importante para a aprendizagem da compreensão leitora. No que se refere à integração dos fatores emotivos, não encontramos sugestões explícitas, mas evidenciamos que seu programa dá relevo à mediação docente, sugerindo uma constante interação com o aluno, com várias sugestões de diálogo, ainda que bastante focadas na ativação dos conhecimentos prévios ou na avaliação de como se processa o pensamento do aluno.

Em um programa mais elaborado, Viana et. al. (2010a; 2010b) e Viana et. al. (2012) apresentam dois programas de ensino explícito da compreensão de leitura intitulados "Aprender a compreender torna mais fácil o saber" e "Aprender a compreender... Do saber ao saber fazer". Os programas são destinados a alunos do $3 .^{\circ}$ ao $6 .^{\circ}$ anos de escolaridade, em Portugal e, segundo as autoras, podem ser desenvolvidos tanto em contexto de sala de aula como em contexto de grupo de apoio/recuperação. As autoras apresentam estratégias de ensino com o recurso ao que chamaram "Família Compreensão", um conjunto de personagens criado para esses programas com o objetivo de modelar, no leitor, o uso das estratégias mais adequadas para executar as tarefas, munindo-o de instrumentos para regular a sua compreensão e superar dificuldades. De acordo com as autoras, os programas focam as competências de ordem superior, no nível da construção de significado (dentro da frase, entre sequências de frases e no texto como um todo), cujo desenvolvimento exige a mobilização de processos orientados para a compreensão dos elementos da frase, processos orientados para a procura de coerência entre as frases, processos visando à construção de modelos mentais dos textos e processos que facilitam uma visão de conjunto, permitindo ao leitor captar os elementos essenciais, levantar hipóteses e integrar a informação aos conhecimentos anteriores.

É importante destacar que Viana (2002) argumenta que a evolução das capacidades cognitivas do aluno está, de certo modo, dependente da estimulação (mais ou menos consciente) do meio em que a criança vive. Para a autora, quando o interesse da criança prossegue, há o desenvolvimento de uma série de competências que lhe vão abrir o caminho para um fácil acesso à leitura, mas quando, por outro lado, não existe ou não é estimulado, o caminho para a leitura tem de ser encontrado com a ajuda do professor. Assim sendo, a simples entrada na escola não seria suficiente para resolver estes problemas. Nessa mesma linha, Viana et. al. (2012) defendem a necessidade de um ensino explícito da compreensão leitora e analisam criticamente a fala docente de que, uma vez dominado o código, a compreensão acontece e de que a utilização de perguntas seria a principal estratégia de ensino da compreensão leitora. As autoras contradizem esse pensamento e defendem que: dominar o código, embora seja uma condição necessária, por si só não garante a compreensão do que é lido; a formulação de perguntas sobre os textos lidos não ensina a compreender; e o acerto na resposta a uma determinada pergunta não é sinônimo de compreensão do que foi lido. Assim, elas elaboram o programa com tarefas concebidas numa perspectiva de ensino orientada para o processo de compreensão.

As autoras comentam que, ao longo dos programas, são apresentadas sugestões que remetem para o que chamam de "diálogo procedimento" que, segundo elas, vai além do padrão de interação perguntaresposta. Conforme afirmam, trata-se de favorecer um contexto de comunicação no qual é estimulada a interação entre alunos e dos alunos com o professor, permitindo não apenas a produção de uma 
resposta, mas também a produção de perguntas, a reflexão sobre o modo como as respostas foram descobertas ou elaboradas e a explicitação da argumentação que as sustenta, pois, como o objetivo é o desenvolvimento da compreensão, consideram mais importante do que as respostas fornecidas a discussão sobre os raciocínios e sobre as razões que levam os alunos a responder de determinado modo. As autoras sugerem que as respostas sejam trabalhadas em grande grupo, por pares de alunos ou individual. Em situação de resposta individual, sugerem que se recorra à autocorreção, seguida de justificação e de discussão das opções, "em particular quando se trata de perguntas com resposta de escolha múltipla, verdadeiro/falso, ordenação, seleção de várias alternativas ou de completamento" (VIANA et al., 2012, p. 450).

Os programas em si consistem em um conjunto expressivo de tarefas de compreensão distribuídas pelos processos de compreensão literal, significado de palavras/extração de significado, compreensão inferencial, reorganização, compreensão crítica e metacompreensão. Essas tarefas são apoiadas por seis personagens, aos quais os alunos podem recorrer em diferentes etapas e que promovem o uso de estratégias metacognitivas. Na criação das personagens, já observamos evidências de preocupação em integrar cognição-emoção nas estratégias de ensino, quando defendem que o objetivo da Família Compreensão é o de, de uma maneira lúdica, explicitar os processos cognitivos envolvidos na compreensão da leitura e, ao mesmo tempo, modelar, através de um conjunto de personagens mais próximas do imaginário infantil, um conjunto de estratégias de abordagem dos textos e das perguntas e tarefas que, a partir deles, são propostas.

No ensino explícito da compreensão da leitura, as autoras distinguem três fases para a exploração dos textos, as quais correspondem ao momento antes, durante e após a leitura. São exemplos fornecidos pelas autoras para o momento anterior à leitura o fornecimento de informações sobre o texto, a formulação de perguntas, estratégias de previsão sobre o texto e o vocabulário e a ativação de conhecimentos prévios. ${ }^{3}$ Com relação ao durante a leitura, as autoras exemplificam com as estratégias de orientar os alunos a destacarem palavras de difícil compreensão, incentivá-los a fazerem previsões e a confrontálas. Para o momento após a leitura, as autoras destacam, entre outras, as estratégias de promover debate sobre a coincidência entre as previsões e o texto lido, completar esquemas e debater os trechos que suscitaram maiores dificuldades.

Como podemos observar, o trabalho de Viana et. al. (2010a; 2010b; 2012) é mais elaborado e apresenta uma forte ênfase nos processos cognitivos envolvidos na leitura, porém, também evidenciamos que a proposta valoriza o lúdico e as interações entre docente e alunos, aspecto favorável à emoção positiva na aprendizagem.

No Brasil, uma proposta amplamente conhecida sobre o ensino da compreensão leitora, com enfoque nas estratégias cognitivas, é o trabalho de Angela Kleiman (2013 [1993]). Nesse trabalho, a autora, de início, já relata sua experiência em oferecer cursos de leitura para professores preocupados com o fato de seus alunos não gostarem de ler. Ela não chega a discorrer sobre esse problema, mas aponta que os professores não sabem como promover condições em sala de aula para o desenvolvimento do leitor, porque não possuem conhecimento teórico sobre a natureza da leitura, problema que seu trabalho com oficinas teve bom êxito em contribuir para minorar. A orientação pedagógica de seu trabalho é, conforme assume, vygotskiana e neovygotskiana, uma vez que entende a aprendizagem como construída na interação de sujeitos cooperativos que têm objetivos em comum. A autora ressalta que essa interação não será homogênea, uma vez que são diferentes os estágios de desenvolvimento dos alunos em sala de aula e, por conseguinte, os potenciais de aprendizagem variarão conforme o desenvolvimento que ela já possui. Cabe, portanto, ao professor, definir tarefas plausíveis e significativas, segundo objetivos pré-definidos em comum acordo (KLEIMAN, 2013, p. 13). A autora também problematiza se as tentativas de um ensino da compreensão leitora não seriam

3 Para uma visão completa dos exemplos, ver Viana et al. (2012). 
incoerentes com a própria natureza da atividade, uma vez que, para ela, a leitura é um ato individual de construção de significado, num contexto de interação entre autor e leitor, de modo que sempre será diferente para cada leitor, dependendo de seus conhecimentos, interesses e objetivos do momento. Ela apresenta como solução a esse problema o rompimento com uma concepção de leitura comum à prática escolar, que privilegia apenas uma possibilidade de leitura como correta e autorizada, a do professor (KLEIMAN, 2013). Seguindo esse pensamento, propõe que o ensino da leitura deve ser entendido como o ensino de estratégias de leitura e como o desenvolvimento de habilidades linguísticas características do bom leitor (KLEIMAN, 2013, p. 74).

As estratégias de leitura são entendidas como operações regulares para abordar o texto, inferidas a partir da compreensão desse texto. São as estratégias cognitivas e as metacognitivas. As estratégias cognitivas são as operações inconscientes do leitor realizadas para atingir algum objetivo. As estratégias metacognitivas são as operações realizadas com um objetivo sobre os quais o leitor tem controle consciente no sentido de ser capaz de explicar a ação. Assim, o ensino estratégico de leitura consistiria na modelagem de estratégias metacognitivas e no desenvolvimento de habilidades verbais subjacentes aos automatismos das estratégias cognitivas (KLEIMAN, 2013, p. 74-76). Para a autora, esse tipo de instrução seria realizado por meio de análise textual característica da desautomatização do processo. Finalmente, apregoa que o ensino de estratégias de leitura consiste em tentar reproduzir as condições que dão ao leitor proficiente condições de flexibilidade e independência, indicativa de uma riqueza de recursos disponíveis. Para esse fim, considera que as ações pedagógicas devem abranger a demonstração para o aluno da importância de ler com um objetivo, ainda que determinado por escolhas pessoais livres. Além disso, todo programa de leitura deve permitir ao aluno entrar em contato com um universo textual amplo e diversificado, para que ele possa se tornar um leitor proficiente, fazendo predições quanto ao conteúdo do texto, apoiadas no conhecimento prévio (enciclopédico, sociocultural e textual).

Do ponto de vista da educação cognitiva que assumimos, evidenciamos que a proposta da autora é coerente com o objetivo de maximizar os potenciais dos alunos para a aprendizagem, a partir do desenvolvimento que o aluno já possui, de modo a fomentar sua autonomia como leitor. No que se refere à mediação, destacamos o papel que a autora dá ao professor como aquele que cria condições para o aluno fazer predições, supre eventuais problemas, construindo suportes para o enriquecimento dessas predições e mobilizando seu maior conhecimento sobre o assunto, antes e durante a leitura, além de auxiliar o aluno a perceber a função dos aspectos linguísticos relacionados à intencionalidade. Do ponto de vista da integração cognição-emoção, embora demonstre, desde a apresentação que encabeça a obra, a preocupação dos professores por seus alunos não gostarem de ler, essa questão não chega a ser aprofundada. Em certo momento, afirma que uma de suas análises não diz respeito ao efeito produzido no leitor (KLEIMAN, 2013, p. 83), porém, podemos inferir pistas da integração cogniçãoemoção quando ela defende que as concepções de texto e de leitura que subjazem as práticas na sala de aula podem ser uma das causas da desmotivação e desinteresse pela leitura, quando sugere uma conversa geral sobre o assunto do texto como fator motivacional, quando defende que todo programa de leitura deve ter um componente livre à escolha do aluno e quando afirma que sua proposta tem o intuito de construir a autoconfiança do aluno em suas estratégias para resolver problemas de leitura (KLEIMAN, 2013, p. 7; 35; 77; 84).

A despeito da variedade geográfica desses estudos, que, em nosso entender, enriquece a discussão, observamos aproximações entre as estratégias de ensino propostas bem como o resultado positivo da aplicação empírica dessas estratégias para a aprendizagem, o que corrobora a hipótese de que existe um padrão mais ou menos homogêneo de estratégias eficazes para o ensino da compreensão leitora, ainda que salvaguardadas as heterogeneidades próprias a cada situação pedagógica. Como podemos observar, é evidente, nos trabalhos supracitados, que a filiação a abordagens cognitivas 
contribuiu para o bom desempenho dos estudantes na avaliação da compreensão leitora. Dessa filiação, identificamos que eles possuem em comum alguns pressupostos basilares sobre o ensino da compreensão leitora: a defesa de que compreensão leitora pode e deve ser ensinada a partir de fundamentos cognitivos; a compreensão de que a aprendizagem deve ser construída na interação entre os sujeitos; o entendimento de que o mediador deve definir tarefas exequíveis segundo objetivos pré-definidos; o foco no ensino de estratégias, com destaque especial à ativação de conhecimentos prévios, à predição leitora, à elaboração de objetivos pré-definidos, às estratégias metacognitivas e à elaboração de inferências.

Não é claro o papel das etapas do desenvolvimento cognitivo e emocional da criança nos programas, embora todas as propostas façam menções a essas etapas, especialmente quando defendem que crianças menores devem receber atenção diferenciada, o que demonstra um entendimento implícito de que existem diferenças na interação a depender da fase de desenvolvimento. De certo modo, os trabalhos parecem concordar em não estabelecer estágios rígidos de desenvolvimento, mas assumem que deve ser observado e considerado o desenvolvimento que o aluno já possui. Quanto às pistas da integração cognição-emoção, não encontramos uma estratégia específica, mas observamos que os programas assumem, em alguma medida, a preocupação em despertar o interesse do aluno, bem como em desenvolver uma aproximação entre o docente e o aluno nas formas de mediação. Contudo, é evidente que os aspectos emocionais da leitura ainda figuram em segundo plano nos programas e, por essa razão, propomos que as estratégias de ensino da compreensão leitora precisam ser incrementadas no que se refere aos aspectos emocionais, uma vez que uma lacuna no desenvolvimento desse componente da cognição pode favorecer a crença numa concepção de ensino de que a mente pode ser isolada dos fatores emocionais no processo de pensamento, o que contrariaria as evidências de Damásio (2012) e, acreditamos, contraria a possibilidade de um desenvolvimento humano pleno.

Desse modo, na próxima seção, buscamos, a partir dos pontos de convergência entre os programas de ensino revisados, propor estratégias de ensino para a integração cognição-emoção que poderiam ampliar a abordagem pedagógica da compreensão leitora, no sentido de favorecer uma educação cognitiva para o desenvolvimento humano mais pleno. Passemos a essa discussão.

\section{Proposições para o ensino da compreensão leitora a partir de uma concepção de educação cognitiva para o desenvolvimento humano pleno}

Nossa proposta de ampliação do ensino da compreensão da leitura, como vimos demonstrando, está inserida em uma abordagem de educação cognitiva, representada neste trabalho pela concepção de Fonseca (2015), na medida em que essa concepção possui fundamentação teórica consistente e bem estabelecida no campo da educação de base cognitiva, apresenta flexibilidade para a aproximação com estudos cognitivos sobre práticas de ensino em áreas específicas do conhecimento, tais como o ensino da compreensão leitora, e valoriza o desenvolvimento cognitivo integrado ao emocional. Cumpre reiterar que nosso desejo é o de impulsionar a pesquisa e a discussão sobre o tema, a fim de contribuir para o ensino da compreensão leitora para o desenvolvimento humano pleno. Por isso, nossa reflexão preserva a flexibilidade de adequação a diferentes situações de aprendizagem, para que docentes tenham a liberdade de planejar conforme os objetivos, o público-alvo e os diferentes contextos.

Nossa proposta consiste em um conjunto de sugestões para o planejamento educativo as quais denominamos "experiências facilitadoras da emoção positiva na aprendizagem da compreensão leitora", pautadas nos parâmetros das práticas de ensino mediatizadas, centradas na cooperação e que busquem potencializar as habilidades de compreensão leitora do aluno, facilitando o seu desenvolvimento e, ao mesmo tempo, favorecendo a reciprocidade emocional, a segurança e o conforto nas tentativas de resolução de problemas. Avalizamos a flexibilidade das experiências sugeridas para atender ao máximo as diferentes situações de ensino, conforme os objetivos pedagógicos e as necessidades discentes. Entendemos que todo o processo de leitura é uma experiência de leitura diferente, a depender dos 
propósitos e da situação, mas, conforme Cosenza e Guerra (2011), a emoção positiva é essencial para que ocorra aprendizagem, e o ambiente de aprendizagem deve ser estimulante e alegre, permitindo o relaxamento e minimizando a ansiedade.

Com efeito, delineamos um conjunto de experiências não ordenadas, que podem ser visualizadas no quadro a seguir.

Figura 1 - Quadro de experiências facilitadoras da emoção positiva na aprendizagem da compreensão leitora

\begin{tabular}{|c|c|}
\hline Experiência & MEDIATIZAÇÃO DOCENTE \\
\hline $\begin{array}{l}\text { Leitura para } \\
\text { a fruição }\end{array}$ & $\begin{array}{l}\text { Disponibilização de texto(s) adequado(s) ao gosto e interesse dos estudantes, } \\
\text { selecionados a partir de interações prévias. } \\
\text { Disponibilização de tempo satisfatório para a leitura por fruição. } \\
\text { Criação de um ambiente agradável e estimulante para a leitura. } \\
\text { Criação de um ambiente afetuoso e seguro para a expressão de pensamentos e } \\
\text { sentimentos a respeito do texto. } \\
\text { Disponibilização de tempo livre para a apreciação estética do texto, sem exigências. } \\
\text { Criação de um ambiente favorável ao desenvolvimento do autoconceito como leitor } \\
\text { e de crenças positivas sobre a leitura. } \\
\text { Criação de um ambiente livre e favorável ao compartilhamento de sensações, } \\
\text { percepções e emoções. }\end{array}$ \\
\hline $\begin{array}{l}\text { Leitura com } \\
\text { o bj et i vo s } \\
\text { pré-definidos }\end{array}$ & $\begin{array}{l}\text { Elaboração cooperativa dos objetivos ou diálogo aberto sobre sua importância. } \\
\text { Elaboração de tarefas agradáveis focadas nos processos de compreensão leitora, } \\
\text { na mobilização dos conhecimentos prévios, na predição, na metacognição, na } \\
\text { elaboração de inferência, entre outros, com pedidos de justificativa e fundamentação } \\
\text { que permitam ao professor observar o desenvolvimento do aluno e interagir como } \\
\text { colaborador desse desenvolvimento. } \\
\text { Elaboração de tarefas de investigação dos estados afetivos despertados pela leitura } \\
\text { e sobre a relação desses estados com a compreensão leitora. } \\
\text { Inclusão de intervalos com tarefas mais lúdicas e/ou relaxantes. } \\
\text { Criação de um ambiente afetuoso e seguro para a expressão de pensamentos e } \\
\text { sentimentos a respeito das tarefas. } \\
\text { Criação de um ambiente cooperativo, afetuoso e seguro para a expressão de } \\
\text { dificuldades e o pedido de ajuda. } \\
\text { Criação de um ambiente favorável à cooperação entre os alunos para superar as } \\
\text { dificuldades. } \\
\text { Emprego do reforço positivo nos avanços observados. } \\
\text { Observação dos estados de ânimo dos alunos e, se necessário, reforçar as estratégias } \\
\text { motivacionais. }\end{array}$ \\
\hline $\begin{array}{l}\text { Leitura para } \\
\text { a repetição } \\
\text { experiencial }\end{array}$ & $\begin{array}{l}\text { Disponibilização de tempo para a reapreciação do texto, após os novos conhecimentos } \\
\text { propiciados a partir das tarefas e da mediação. }\end{array}$ \\
\hline Projeções & $\begin{array}{l}\text { Proposição de espaço para novas criações, em que os novos conhecimentos possam } \\
\text { ser generalizados para outras situações e contextos, favorecendo a memória, a } \\
\text { consciência e a criatividade. } \\
\text { Elaboração de projetos cooperativos (podendo ser interdisciplinares) que permitam } \\
\text { o uso das diferentes habilidades desenvolvidas por cada estudante, evitando-se a } \\
\text { competição. } \\
\text { Observação e avaliação coletiva do processo para o planejamento de novas ações, } \\
\text { considerando-se as motivações. }\end{array}$ \\
\hline
\end{tabular}

Fonte: Elaboração da autora, 2018. 
Como podemos observar, nossa proposta considera todas as estratégias de ensino da leitura como um tipo de experiência de leitura. Embora não tenhamos pretendido estabelecer uma sequência ordenada dessas experiências, parece-nos, com base em nossos fundamentos teóricos, que despertar o prazer pela leitura é o alicerce para a aprendizagem, antes mesmo da ativação dos conhecimentos prévios, que, tradicionalmente, é a estratégia mais usual nesse ensino. Também assumimos que a leitura por fruição não compromete o ensino mais sistematizado da compreensão leitora. Pelo contrário, o próprio ato de perceber e observar o texto e o suporte, como ocorre na leitura autêntica, e o compartilhar livremente as experiências de leitura já exercem um papel na ativação do conhecimento prévio, e isso com a vantagem de se dar de forma mais espontânea e menos ansiosa, fatores essenciais para que ocorra a aprendizagem (COSENZA e GUERRA, 2011). Do mesmo modo, ao contrário do pensamento comum de que a motivação se concentra apenas no momento inicial de uma proposta pedagógica, entendemos que a indução da emoção positiva deve constituir todo o processo de ensino. Defendemos, a partir de Damásio (2012), que as emoções sempre estão presentes, independentemente de o mediatizador percebê-las ou não. Por essa razão, consideramos vantajosas as estratégias de possibilitar senti-las, de auxiliar a regulá-las, de observar os estados de ânimo, de favorecer o diálogo de conscientização e de reforçar a emoção positiva na leitura. Com isso, ampliamos a concepção de ensino da compreensão leitora, aproximando-a mais da vida real, e concedemos à aula de leitura o status de sustentáculo para o desenvolvimento humano pleno na escola.

Embora a discussão de nossa proposta pudesse ser encerrada aqui, entendemos que, antes de passarmos à conclusão deste trabalho, cabe um comentário adicional. Ainda que valorizemos a emoção positiva no ensino, não queremos dizer, com isso, que cabe ao docente ter gerência sobre as emoções dos alunos, algo que, além de inviável, é incompatível com a concepção de educação que adotamos. Por isso, buscamos empregar expressões como "criar um ambiente", "favorecer", "facilitar". Com isso, nosso objetivo é o de sugerir experiências que propiciem a indução da emoção positiva em leitura, em um ensino que não descarte, antes, pelo contrário, valorize esse aspecto constitutivo da cognição e, por conseguinte, favoreça a aprendizagem. A esse respeito, vale, aqui, lembrar que Damásio (2012) já afirmava que nossas estratégias de raciocínio são defeituosas para lidar com a incerteza e a complexidade das questões pessoais e sociais, e, na tentativa de utilizarmos nossa capacidade de decisão, somos influenciados pela mobilização de outros recursos, porque corpo e mente estão integrados e “o organismo tem algumas razões que a razão tem de utilizar" (DAMÁSIO, 2012., p. 184).

Por fim, queremos destacar que a leitura, por si só, já provoca emoções, e dialogar sobre os efeitos emocionais da leitura pode cooperar, inclusive, para o aprimoramento do ensino de estratégias metacognitivas, que também recebem a influência de emoções. Desse modo, entendemos que o trabalho com as emoções na aula de leitura contribui, por um lado, para favorecer a aprendizagem da compreensão leitora e, por outro, para a compreensão de si mesmo, como leitor e como sujeito, promovendo uma educação para um desenvolvimento humano mais integral e pleno.

\section{Conclusão}

Neste trabalho, elaboramos sugestões de experiências facilitadoras da emoção positiva em leitura para construir uma proposta de ensino da compreensão leitora voltada ao desenvolvimento humano pleno. Assim, revisamos uma concepção de educação cognitiva, reconhecida por sua consistência teórica e fortemente embasada em estudos renomados sobre a complexa arquitetura cognitiva, e buscamos identificar pontos de convergência em três programas de ensino da compreensão leitora, igualmente consistentes em seu aporte teórico e com eficácia validada empiricamente. A partir dessa 
revisão, constatamos lacunas quanto à valorização dos aspectos emocionais nas propostas de ensino examinadas e propusemos uma abordagem de ensino mais abrangente, que explore, conjunta e efetivamente, os aspectos cognitivos e emocionais da leitura e da aprendizagem da compreensão leitora. Observamos que o diálogo entre os diferentes aportes teóricos dos quais nos valemos mostrou-se muito promissor e revelou a necessidade de construção de uma agenda de pesquisas na área para o aperfeiçoamento dessas práticas pedagógicas mais integradoras. Finalmente, buscamos ampliar a concepção de ensino da compreensão leitora, aproximando-a mais da leitura na vida real, e concedemos à aula de leitura o status de sustentáculo para o desenvolvimento humano pleno na escola. 


\section{Referências}

ALMEIDA, Geraldo. Neurociência e sequência didática para a educação infantil. 2.ed. Rio de Janeiro: Wak Editora, 2015.

CASTRO, Joselaine Sebem de. A influência do conteúdo emocional na recordação de textos: uma abordagem conexionista. Doutorado em Linguística e Letras Instituição de Ensino: Pontifícia Universidade Católica do Rio Grande do Sul, Porto Alegre, 2004.

CITRON et al. Emotional valence and arousal affect reading in an interactive way: Neuroimaging evidence for an approach-withdrawal framework. Neuropsychologia, Vol.56, abr., 2014, p.79-89.

BORGES, Karina; BELLO, Suzelei; MACHADO, Andréa. (Org.) Neuropsicologia e Aprendizagem. São Carlos: Pedro e João, 2014.

COELHO, Nelly Novaes. Literatura infantil: teoria, análise, didática. São Paulo: Moderna, 2000.

COSENZA, Ramon M.; GUERRA, Leonor B. Neurociência e educação: como o cérebro aprende. Porto Alegre: Artmed, 2011.

DAMASIO, António. O erro de Descartes. Emoção, razão e o cérebro humano. 3. Ed. São Paulo: Companhia das Letras, 2012.

FONSECA, Vitor. Cognição, neuropsicologia e aprendizagem. Abordagem neuropsicológica e psicopedagógica. 7. Ed. Petrópolis: Vozes, 2015.

KLEIMAN, Angela. Oficina de leitura: teoria e prática. 15. Ed. Campinas: Pontes, 2013.

LARROZA, Elenice. Leitura: emoção, prazer. Dissertação. Mestrado em Letras. Universidade Católica de Pelotas, Pelotas, 2001.

LEÓN, Jose et al. Effects of valence and causal direction in the emotion inferences processing during reading: Evidence from a lexical decision tas. Anales de Psicología. Vol. 31 iss: 2, jan., 2015, p. 677 $-686$.

LOPEZ, Nuria; TAPIA, Jesus. Como ensinar a compreender um texto? Um programa de estratégias para treinar a compreensão leitora. Petrópolis: Vozes, 2016.

PULIEZI, Sandra. Fluência e Compreensão na Leitura de Textos. Um estudo com crianças do quarto ano do Ensino Fundamental. Tese. Doutorado em Psicologia da Educação. Pontifícia Universidade Católica de São Paulo, São Paulo, 2015.

SCHIAVO, Adriana Ap. Noronha; RIBÓ, Cristiane M. Escamilhas. Estimulando todos os sentidos de 0 a 6 anos. Seminário do $16^{\circ}$ COLE. Congresso de Leitura do Brasil. UNICAMP, Campinas, 2007. Disponível em http://alb.com.br/arquivo-morto/edicoes_anteriores/anais16/sem13pdf/sm13ss17_01. pdf. Acesso em 15/01/2018.

VIANA, F. L. RIBEIRO, I. S., FERNANDES, I., FERREIRA, A., LEITÃO, C., GOMES, S., MENDONÇA, S.; PEREIRA, L. O ensino da compreensão leitora. Da teoria à prática pedagógica. Coimbra: Almedina, 2010a.

VIANA, F. L. RIBEIRO, I. S., FERNANDES, I., FERREIRA, A., LEITÃO, C., GOMES, S., MENDONÇA, S.; PEREIRA, L. Aprender a Compreender torna mais fácil o saber. Coimbra: Almedina, 2010b.

VIANA, F. L.; CADIME, I; SANTOS, S.; BRANDÃO, S.; RIBEIRO, I. O ensino explícito da compreensão da leitura. Análise do impacto de um programa de intervenção. Revista Brasileira de Educação, v. 22 n. 71, 2017. Disponível em http:/www.scielo.br/pdf/rbedu/v22n71/1809-449Xrbedu-22-71-e227172.pdf. Acesso em 15/01/2018. 